\title{
'Dare to Be Different': Enhancing life skills education for HIV prevention in South African schools
}

Tobey Nelson Sapiano

Nathi Sohaba

Eka Esu-Williams

Follow this and additional works at: https://knowledgecommons.popcouncil.org/departments_sbsr-hiv

Part of the Demography, Population, and Ecology Commons, Family, Life Course, and Society Commons, Gender and Sexuality Commons, International Public Health Commons, and the Medicine and Health Commons How does access to this work benefit you? Let us know!

\section{Recommended Citation}

Nelson Sapiano, Tobey, Nathi Sohaba, and Eka Esu-Williams. 2008. "'Dare to Be Different': Enhancing life skills education for HIV prevention in South African schools," Horizons Research Summary. Washington, DC: Population Council. 


\section{“DARE to be Different:" Enhancing LIFE SKILLS EDUCATION FOR HIV Prevention in South African Schools}

$7 \mathrm{n}$ South Africa, one of the countries hardest hit by the AIDS epidemic, approximately 5.5 million people are living with HIV (UNAIDS 2006). Reaching young South Africans with effective prevention programming has become key to slowing the rate of HIV infection and to ensuring a stronger future for the country. One of the main strategies the South African Government has used to build HIV prevention awareness and promote behavior change among young people is school-based life skills education, which is part of the Life Orientation Programme. The National Department of Education has made this an educational priority for grades one

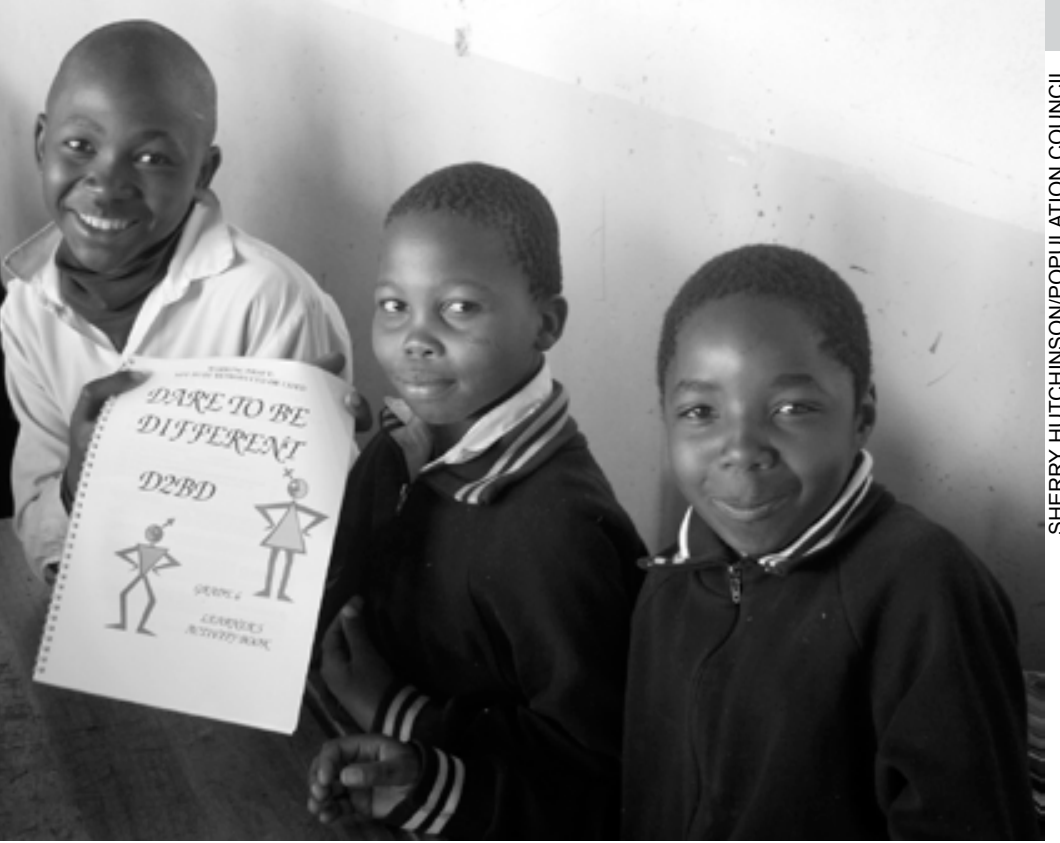

Sixth grade students at Evulingqondo Primary School and the "Dare to Be Different" learner's activity book.

through 12 . An estimated 12 million youth attending approximately 26,000 schools participate in these classes, which use HIV prevention messages and education to reach both youth who have not yet engaged in high-risk sexual behaviors and those who have.

Since 2000, the Horizons Program has conducted research exploring the impact of life skills education and other school-based HIV prevention activities on young South Africans. Findings from one study, conducted in collaboration with the Medical Research Council in KwaZulu Natal, identified gaps in HIV prevention information targeted to in-school youth

To read more about this study, go to www.popcouncil.org/horizons/projects/SouthAfrica_ABLifeSkillsCurriculum.htm
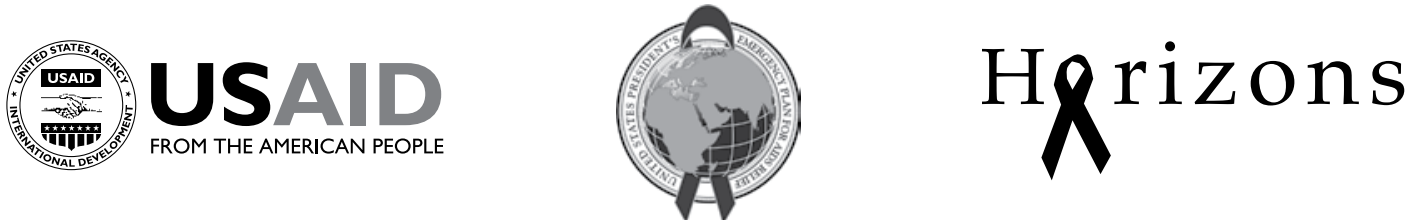
and concluded that life skills programming must be comprehensive and involve teachers in the planning phase (Reddy et al. 2001). A later Horizons study, also conducted in KwaZulu Natal, found that youth enrolled in Life Orientation classes were more likely to increase their condom use as a way to prevent HIV infection than engage in abstinence or decrease their number of partners (The Transitions to Adulthood Study Team 2003).

The same study also revealed that life skills programs in South Africa have more impact on younger youth (ages 10 to 14 ) than older youth (ages 15 to 24 ). In fact, this younger age group-bridging childhood and adolescence-presents a special window of opportunity in South Africa for HIV prevention. In contrast to the high HIV prevalence among older youth ages 15 to 24, estimated to be over 10 percent, prevalence for youth ages 10 to $14-$ most of whom have had limited or no sexual experience-is estimated at just over 1 percent (Shisana et al. 2005; Reddy et al. 2001). In addition to having far lower levels of infection, Horizons researchers found that young people 10 to 14 years old are particularly receptive to messages about abstinence or delaying sex and being faithful (The Transitions to Adulthood Study Team 2003).

To improve HIV prevention programming for this age group, Horizons, in collaboration with education specialists and representatives from South Africa's National Department of Education:

- Developed a program for sixth and seventh grade learners that promotes a balanced "ABC" strategy, emphasizing abstinence (A) and being faithful (B), while building upon existing condom (C) knowledge.

- Built the capacity of teachers to implement and deliver the program within the existing Life Orientation curriculum.

- Assessed the feasibility, relevance, and acceptability of the program among teachers and learners.

\section{Developing and Implementing "Dare to be Different"}

To develop the program, Horizons and partners conducted three activities: a consultative workshop, curriculum development, and pilot testing of the curriculum module. The consultative workshop with program implementers and stakeholders, including representatives of South Africa's National and Provincial Departments of Education and Health and the U.S. Agency for International Development, took place in February 2006. Its purpose was to discuss the need for and feasibility of integrating AB-related activities and messages into life skills programs.

Based on overwhelmingly positive feedback from the meeting and from discussions with the Department of Education, Horizons decided to move ahead in the development of an AB life skills curriculum to supplement the school-based Life Orientation Program.

A locally-based project team, made up of education specialists and curriculum developers, conducted the following activities to inform the development of the "Dare to Be Different" (D2BD) module:

- A rapid assessment of the Department of Education's Life Skills and HIV and AIDS Education Programme.

- A comprehensive literature review of both schoolbased and non-school-based life skills and HIV prevention programs.

- A series of advocacy meetings with representatives of the Mpumalanga Provincial Department of Education, community members, teachers, parents, and learners; and a pilot test of the curriculum with learners and teachers.

The resulting D2BD module includes messages that promote the advantages of abstinence and faithfulness/mutual monogamy and highlight the consequences of risky sexual engagement, and includes activities that foster:

- Self-awareness.

- Social development.

- Personal development.

- Goal setting.

- Character building.

D2BD also incorporates activities to build such critical skills as decision making, critical thinking, problem solving, negotiation, resisting peer pressure, and communication.

D2BD consists of two distinct sets of materials for the sixth and seventh grades. Each is tailored to reflect nationally established learning outcomes and assessment 
standards for that grade, and the content of each is developmentally appropriate for the age group most closely associated with that grade. For example, the seventh grade material contains more specific information on sexually transmitted infections and uses slightly more advanced terminology, examples, and activities compared to the sixth grade material. Both levels include a teacher manual, learner activity books, and a dictionary.

The teacher manual is designed to provide comprehensive information and guide the life orientation educators on how to conduct the activities. The educators are encouraged to familiarize themselves with the entire teacher's manual before they start implementing the program. The learner activity books are distributed at the start of each lesson, and are meant to supplement the activities outlined in the teacher manual. There are six units for sixth grade and seven units for seventh grade, each including approximately seven activities (Box 1).

D2BD features two components in each unit that make it unique and set it apart from other HIV prevention curricula: Home Talk and Peer Support. Home Talk is a series of take-home activities that the learner completes with a parent or guardian and is a required component of the program. This is a very crucial part of the program, as it seeks to build communication between learners and their parents/guardians on issues around sexuality. Peer Support is a series of optional activities conducted by same-age peers under the guidance of the teacher. Peer Supporters are not peer educators; their primary purpose is to serve as a liaison between the learners and the teachers by assisting the teacher with small group activities and role plays, helping with school

\section{Box 1 Dare to Be Different Curriculum \\ Dare to Be Different ( $6^{\text {th }}$ Grade)}

Unit 1: Dare to Be Different Unit 2: Dare to Be Free

Unit 3: Dare to Make Wise Choices

Unit 4: Dare to Do Friendships Differently

Unit 5: Dare to Say No

Unit 6: Dare to Make a Commitment
Unit 1: Radically Different

Unit 2: Radical Moves Unit 3: Radical Freedom Unit 4: Radical Choices

Unit 5: Radical Relationships

Unit 6: Radical Skills

Unit 7: Radical Perseverance awareness projects, and refering learners who need greater assistance to the teacher.

Between April and July 2007, an expanded pilot of the D2BD curriculum module was conducted in primary schools in Mpumalanga Province to assess the feasibility of incorporating D2BD into the existing Life Orientation Programme. Teachers implementing the module attended a one-day training session conducted by Horizons. The training introduced the teachers to the module, provided information on HIV/AIDS, and distributed monitoring forms that teachers were expected to fill out each time they completed a unit. Weekly monitoring visits took place at each school to see if the implementation was running smoothly and to document key challenges and achievements.

\section{Study Sites}

The study team collected qualitative data from learners and teachers at nine schools in three sub-regions-Balfour, Carolina, and Ermelo-within the Gerte Sibande District Municipality in Mpumalanga Province. Mpumalanga is a highly accessible, predominantly agricultural province in eastern South Africa with approximately 3 million people; mining and timber production are also important. The population is highly mobile, with widespread poverty. SiSwati and IsiZulu are the two primary languages, followed by IsiNdebele and Sepedi.

The Provincial Department of Education identified Gerte Sibande District as urgently needing school-based HIV prevention interventions that build skills as well as provide HIV prevention messages. In each of three subregions, three primary schools were chosen that reflect different socioeconomic conditions within South Africa: one urban school, one rural school, and one school considered to be a "farm" or "mine" school. All sixth- and seventh grade Life Orientation classes in all nine schools participated. Table 1 shows the number of learners and classes for each participating school that took part in the pilot testing of $\mathrm{D} 2 \mathrm{BD}$.

\section{Data Collection and Analysis}

In July 2007 the research team collected qualitative data from teachers and learners in all participating schools through interviews and focus group discussions. Individual interviews were conducted with 15 teachers: 6 
Table 1 Profile of schools by district

\begin{tabular}{lccccc}
\hline Sub-region & School & $\begin{array}{c}\text { \# of 6th grade } \\
\text { classes }\end{array}$ & $\begin{array}{c}\text { \# of 6th grade } \\
\text { learners }\end{array}$ & $\begin{array}{c}\text { \# of 7th grade } \\
\text { classes }\end{array}$ & $\begin{array}{c}\text { \# of 7th grade } \\
\text { learners }\end{array}$ \\
\hline Balfour & School 1 & 3 & 134 & 3 & 132 \\
& School 2 & 2 & 68 & 2 & 82 \\
& School 3 & 3 & 136 & 3 & 125 \\
Carolina & School 1 & 1 & 55 & 1 & 53 \\
& School 2 & 5 & 250 & 5 & 224 \\
Ermelo & School 3 & 1 & 11 & 1 & 10 \\
& School 1 & 2 & 53 & 2 & 40 \\
Total & School 2 & 1 & 42 & 1 & 40 \\
\hline
\end{tabular}

*Identifiers have been removed.

sixth grade teachers, 7 seventh grade teachers, and 2 teachers who taught both sixth and seventh grade at their schools. More than 75 percent of interviewees were female teachers, reflecting the predominance of women on the staff of local schools. One sixth- and one seventh grade Life Orientation teacher were randomly selected from each school to participate in the interviews.

The research team also conducted individual interviews with 36 randomly selected learners: 18 sixth graders and 18 seventh graders, evenly divided by sex. Two learners (one male and one female) per grade at each of the nine schools were randomly chosen for the interviews. Mixed sex focus group discussions (FGDs) were conducted with 175 randomly selected learners. All interviews and FGDs were conducted in the language most comfortable to the interviewee(s).

After data collection, the research team reviewed interview transcripts and determined key themes for coding and interpretation of study findings, then analyzed transcripts for all the FGDs and interviews using the qualitative analysis software ATLAS.ti.

\section{Ethical Considerations}

The study received ethical approval from the Population Council's Internal Review Board and the University of Witwatersrand's Ethics Review Committee. Horizons also met with officials from the Department of Education in Mpumalanga Province, who gave approval for the study.

Working with the schools, the study team sent home a letter with the learners to inform their parents about the program, and in some cases, conducted sensitization meetings with parents to further explain the curriculum's aims and messages. Learners selected for data collection received information sheets about the program and consent forms for their parents to sign. Parents were generally aware of the program because they had already received information letters about it and had been invited to participate in the sensitization meetings. An initial and follow-up distribution of consent forms resulted in a 100 percent consent rate by the learners' parents or guardians. The research team also sought assent from the learners themselves and from the teachers prior to data collection.

\section{Key Findings}

\section{Teachers and learners feel positive about D2BD.}

You will never find a child who is unhappy when we are doing D2BD; even if it is not my Life Orientation period, the learners come to me and ask me to come back to the class and finish up the D2BD activities that we didn't get to finish.... 
It is very interesting to learners; you can see that they are very energetic during this period.

Life Orientation teacher, sixth and seventh grades

The data revealed that both teachers and learners felt overwhelmingly positive about the $\mathrm{D} 2 \mathrm{BD}$ module. During interviews most teachers also reported that $\mathrm{D} 2 \mathrm{BD}$ easily fit into the existing Life Orientation Curriculum. Teachers appreciated the learner-centered approach and the clear and comprehensive messaging and skills-building activities. They also felt that including assessment criteria and detailed lesson plans were two of the most positive aspects of the $\mathrm{D} 2 \mathrm{BD}$ module.

D2BD is excellent: It is fruitful and productive work for learners. It encourages them to know themselves and to be responsible for their lives.

Life Orientation teacher, seventh grade

Learners enjoyed the activities and found them ageappropriate and engaging. Both teachers and learners appreciated that D2BD incorporated topics, activities, and scenarios applicable to the current lives of youth in South Africa.

I liked the activities. They are teaching us about real life, using real stories about things that are really happening now.

\section{Sixth grade learner}

The majority of learners were able to engage in informed discussions about the $\mathrm{ABC}$ behaviors and provide definitions for the behaviors after participating in $\mathrm{D} 2 \mathrm{BD}$. Learners agreed that D2BD encouraged more frequent discussion about HIV prevention and enabled them to identify behaviors that put them at risk for HIV and pregnancy.

\section{Learners want more than just HIV prevention information.}

Teachers and learners generally agreed that D2BD does more than provide the basics of HIV prevention by building critical thinking and decision-making skills, fostering communication about HIV, and encouraging learners to identify risky behaviors and recognize the consequences of those behaviors.

\section{$D 2 B D$ changes the way the child thinks and it changes the learner's behavior. D2BD challenges learners to behave, to resist peer pressure, and to understand the consequences of their actions. \\ Life Orientation teacher, sixth grade}

One objective of $\mathrm{D} 2 \mathrm{BD}$ was to encourage critical thinking about HIV prevention and adolescent sexual and reproductive health in a safe and supportive learnercentered environment. As a result, learners interviewed singly and in focus groups said they want more infor-
All learners were excited about learning new information and skills and were eager to continue with D2BD. They appreciated being included in the learning process and reported that the learner-centered approach made learning more enjoyable and the information easier to retain. Focus group discussions and interviews revealed that learners felt more confident that they could abstain from sex, resist peer pressure, and identify and reduce risky behaviors.

\section{D2BD taught us that if you don't} submit to peer pressure and your friends think that you are boring, you can tell them that you'd rather be boring than do wrong things. If you make the right choices you will be able to build a brighter future.

Seventh grade learner

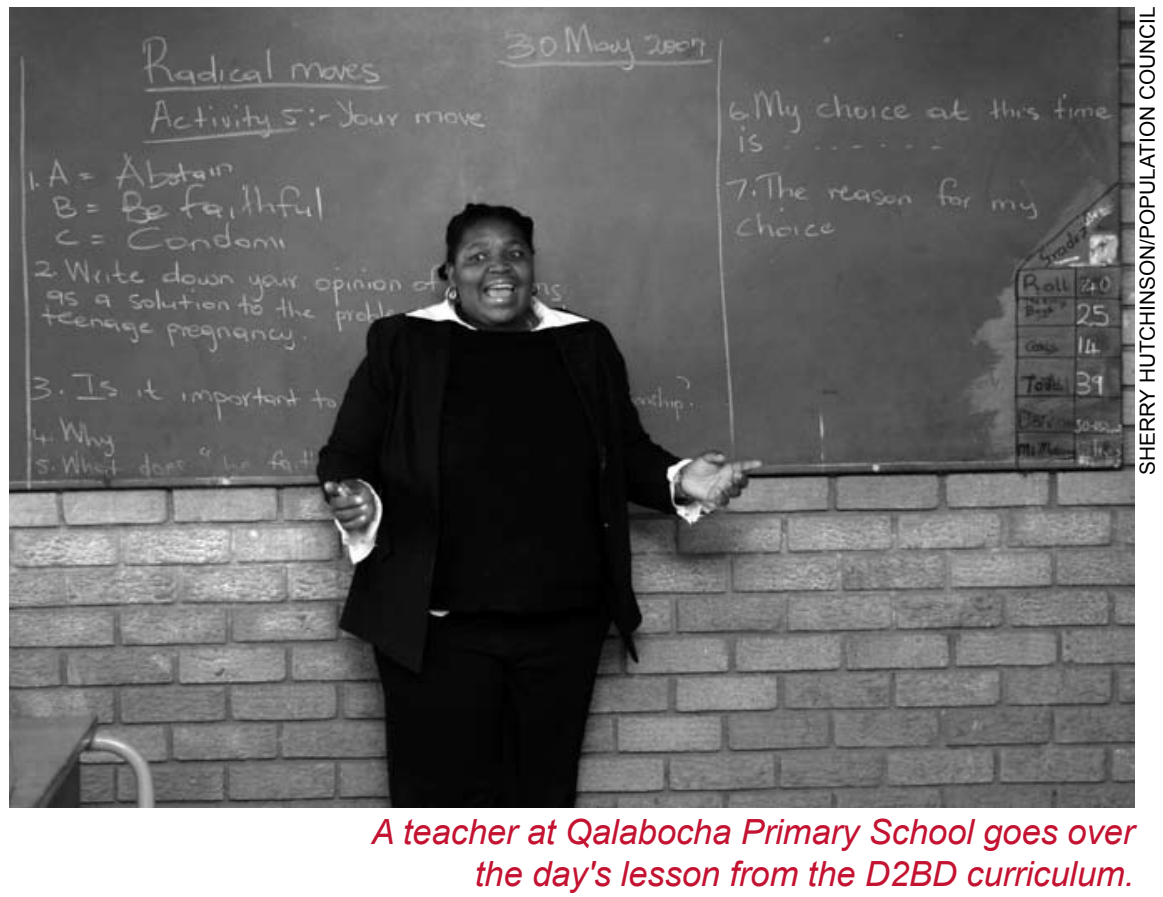




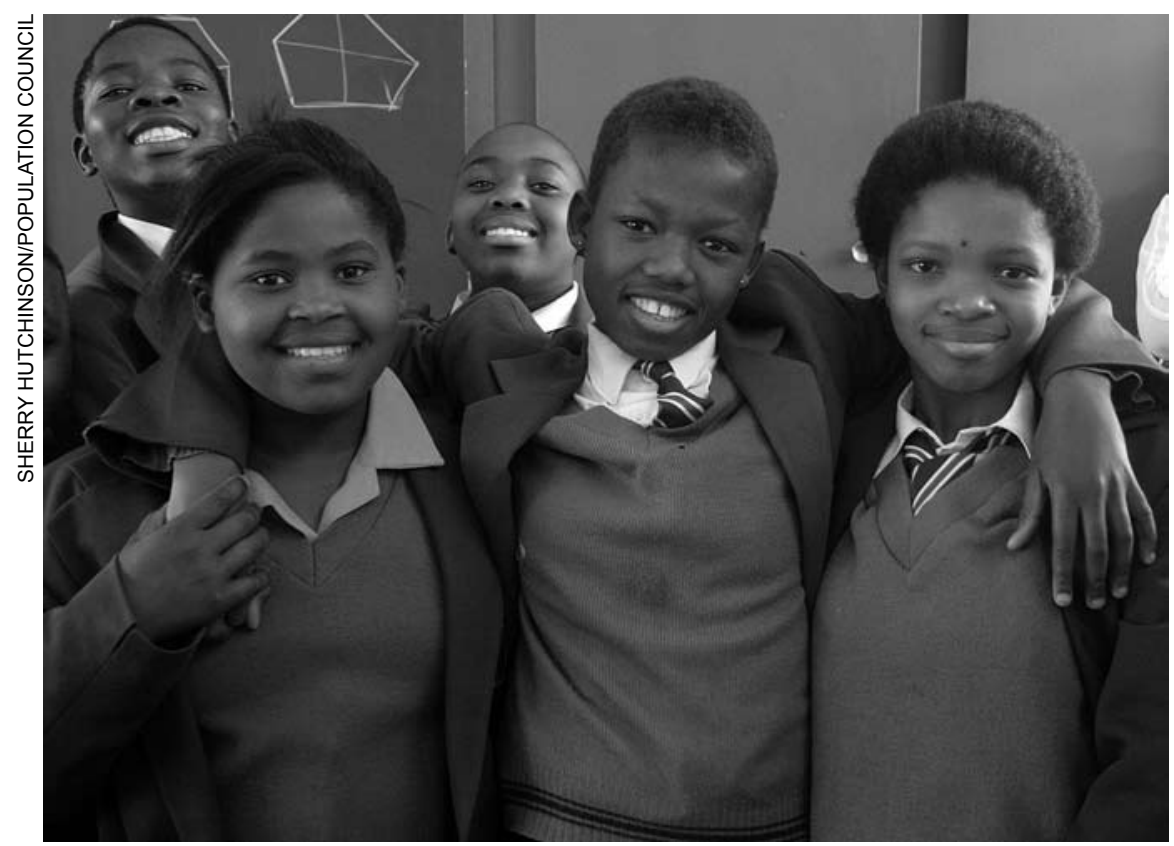

Sixth-grade students at Ermelo Primary School who participated in the D2BD program.

mation on a range of HIV prevention and sexual and reproductive health issues.

Learners, particularly girls, expressed interest in learning more about rape, sexual violence, and sexual coercion. Learners also highlighted the need for more information on how to access health-related services and HIV support services within their community. Both learners and teachers expressed a desire for more information about preventing and treating other infectious diseases, including tuberculosis and malaria.

\section{D2BD enhances the Life Orientation Programme.}

According to both teachers and learners, D2BD has unique features that differentiate it from the Department of Education's existing HIV prevention component within Life Orientation classes. For example, D2BD provides more specific information about HIV/STI prevention and transmission. D2BD is learner-centered and provides ample opportunity for self-expression and creativity through role-plays, games, singing, and topical discussions. Complete lesson plans for each unit, including assessment criteria, a peer support component, and the Home Talk parent-child communication activities, all set $\mathrm{D} 2 \mathrm{BD}$ apart from the current program.
Dare 2 Be Different gives our current Life Orientation a spice...... it involves learners and encourages full participation.

Life Orientation teacher, sixth grade

Since [starting D2BD] the children put notes on my table. The notes say, 'I've stopped this [sexual behavior] and I want to have a better life now.'

Life Orientation teacher, seventh grade

Learners felt that D2BD provides them with a safe space to communicate openly and honestly about sensitive issues that they do not regularly get to discuss. D2BD uses practical examples and stories that the learners can easily identify with.

I love D2BD! It guides us on how to grow up and makes us proud of ourselves. It teaches us good values and empowers us to have a better future.

Seventh grade learner

\section{D2BD improves parent-child communication.}

Many teachers felt the Home Talk component of D2BD presented a unique opportunity to involve parents in their children's sexuality education. Teachers said that this was an important method of reinforcing what learners were hearing in the classroom that could encourage learners to adopt positive behavior. Some teachers, though, did report initial resistance from parents and learners.

At first learners were scared to talk to their parents, but after the first Home Talk activity it got easier and easier. The learners and the parents enjoyed it.

Life Orientation teacher, seventh grade

Many learners reported that they felt more comfortable discussing HIV with their parents and/or guardians following $\mathrm{D} 2 \mathrm{BD}$.

My mother used my [D2BD] activity book to teach me; she explained some of the things in the 
book... I learned to speak to my mother about everything with $D 2 B D$.

Sixth grade learner

\section{Challenges to implementation remain.}

One of the major challenges during implementation was insufficient time. An over-committed school schedule, a lengthy teachers' strike, and a short implementation period all contributed to this. Learners and teachers felt that the lessons were rushed and that important topics were not given enough time.

I would rather take more time and see that the children understand what we are doing instead of rushing them through. We should be able to take as much time as we need because we want to save lives.

Life Orientation teacher, seventh grade

Language was another challenge. The curriculum was designed and implemented in English, a language in which not all learners and teachers were entirely comfortable. Teachers were often unable to provide translations into local languages that learners understood. Learners said that although teachers did their best to explain the activities, there were certain words they could not understand.

There was notable variation in knowledge among the learners on issues related to HIV and sexual health. This presented a challenge for teachers who had to take additional class time to bring less informed learners up to the same knowledge level. Some teachers also lacked knowledge about the sexual health issues discussed.

It was a challenge to teach, as it was new information for me as well as the learners, but it was a nice challenge to give these children knowledge that they need for life. It was a good challenge!

Life Orientation teacher, sixth grade

\section{Conclusions and Next Steps}

According to study respondents, the Life Orientation Programme was easily able to incorporate D2BD into its existing curriculum. With a stronger focus on abstinence and partner reduction, the D2BD module helped fill serious gaps in the Life Orientation Curriculum. Teachers, learners, and parents were enthusiastic about $\mathrm{D} 2 \mathrm{BD}$, cit- ing its learner-centered approach and such components as Home Talk, which helped bridge the communication gap on difficult issues between learners and their parents. A more rigorous evaluation is necessary to determine whether D2BD can have an impact on sexual behavior and knowledge.

Horizons plans to revise the curriculum module based on the pilot's findings to further improve its acceptability and usefulness among teachers and learners. In 2008, Horizons will conduct a more rigorous evaluation of D2BD among sixth and seventh grade learners at 30 schools throughout Mpumalanga Province. $\mathbb{R}$

March 2008

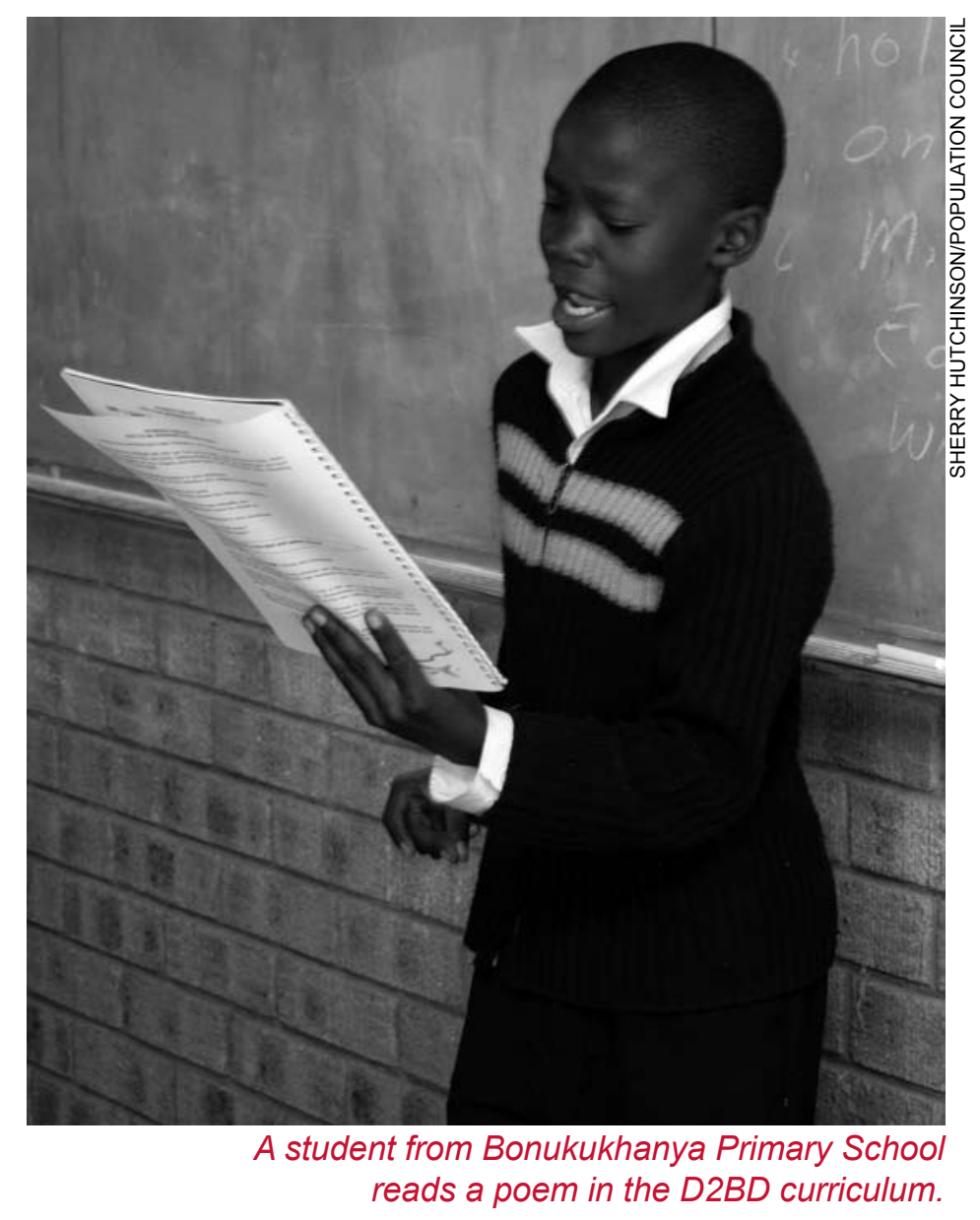




\section{References}

Reddy, Priscilla et al. 2001. "Programming for HIV prevention in South African schools," Horizons Research Summary. Washington, DC: Population Council.

Shisana, O. et al. 2005. South Africa National HIV Prevalence, HIV Incidence, Behavior and Communications Survey. Cape Town: HSRC Press.

The Transitions to Adulthood Study Team. 2003. "Transitions to adulthood in the context of AIDS in South Africa: The impact of exposure to life skills education on adolescent knowledge, skills, and behavior," Horizons Final Report. Washington, DC: Population Council.

UNAIDS. 2006. "2006 report on the global AIDS epidemic." Geneva: UNAIDS.

\section{Acknowledgments}

We would like to thank Thandi Mini for providing monitoring support; Kenau Swart, Darleen Edwards-Meyer, and Nelia Louw for curriculum development; Progressus Research and Development Group for data collection; and the Mpumalanga Provincial Department of Education for the help with all facets of the study. In addition we would like to thank the participating schools, educators, and learners in the Mpumalanga Province.

Principal investigators from this study include Tobey Nelson Sapiano, formerly Horizons/International Center for Research on Women; Nathi Sohaba, Horizons/Population Council; and Eka Esu-Williams, formerly Horizons/Population Council.

Suggested citation: Sapiano, Tobey Nelson, Nathi Sohaba, and Eka Esu-Williams. 2008. "'Dare to be different:' Enhancing life skills education for HIV prevention in South African schools," Horizons Research Summary. Washington, DC: Population Council.

\section{Hqrizons}

Population Council/Horizons

Communications Unit

4301 Connecticut Avenue, NW

Suite 280

Washington, DC 20008

\section{(P Population Council}

Tel: 202-237-9400

Fax: 202-237-8410

horizons@popcouncil.org

www.popcouncil.org/horizons
This research summary is made possible by the generous support of the American people through the United States Agency for International Development (USAID) and the President's Emergency Plan for AIDS Relief under the terms of HRN-A-00-97-00012-00. The contents are the responsibility of the Horizons Program and do not necessarily reflect the views of USAID or the United States Government. 